\title{
Review on Life Education for College Students under the Background of Epidemic
}

\author{
Xueqin Liu \\ Shandong Transport Vocational College, Weifang, Shandong, 261206, China
}

\begin{abstract}
The outbreak of COVID-19 in 2020 put the major issue of life education on the agenda again. For young students, life education can not only help them have an objective, comprehensive and dialectical understanding of life, but also help to improve the quality of their whole life. Colleges and universities should carry out life education courses for students from the perspective of gratitude for life, awe of life, confronting death and achieving life. In addition, colleges and universities should also explore the establishment of a normalized Long-term mechanism to enrich the realization channels of life education, and adhere to the education mode combining school guidance with extracurricular practice.
\end{abstract}

Keywords: Life Education; Gratitude for Life; Awe of Life; Achieve Life; Realization Channel; Education Mode.

\section{Introduction}

The outbreak of COVID-19 with an awful lot of force has brought a terrible atmosphere to the whole world since the beginning of 2020. This sudden plague is a great disaster for all mankind. Tao Xingzhi, a famous educator, said that life is education. For schools, it is of great significance and imperative to guide and educate young students on the concept of life in combination with the era background of epidemic prevention and control.

\section{The Significance of Life Education}

Over the years, although the state has been promoting quality education, under the framework of exam-oriented education mode, more schools are still inclined to utilitarian education of performance appraisal, and often neglect the starting point of education, namely "life education." The outbreak of COVID-19 in 2020 pushed the topic of "life education" in front of the whole society and even whole mankind. The Outline of the National Medium and Long Term Education Reform and Development Plan (2010-2020) clearly puts forward the requirements of stressing on "safety education, life education, national defense education and sustainable development education". It is also emphasized in the guiding opinions on the organization and management of online teaching in Colleges and Universities during the epidemic prevention and control period issued by Ministry of Education, that "focus on strengthening patriotism education, life education and mental health education".

\subsection{Life Education Helps Students Learn to Treat Life Dialectically}

In recent years, malignant events occur frequently in colleges and universities such as fight, taking drugs, depression, suicide, etc., and mental diseases emerge in an endless stream. As educators, we must reflect on the problems existing in school education and face the serious consequences caused by the lack of life education. We should make students understand the value and fragility of life and know how to pay gratitude for life and cherish life through life education.

College students are in the stage of shaping values and outlook on life, and their emotions are also sensitive and changeable. Online statistics show that the college students' anxiety is greater than that of adults. It is the common case in life that many students will become depressed when they encounter a little setback, and even commit self-mutilation or suicide. Therefore, we need to strengthen the guidance to students, lead them to understand the essence of impermanence of life, and help them dialectically look upon the ups and downs encountered in life, to promote their ability to withstand frustrations. 


\subsection{Life Education Helps to Improve Students' Quality of Life}

An important content of life education is to guide students to confront death. Chinese people have always avoided talking about death, but the great philosopher Heidegger advocated "Being-towardsdeath". Through life education, we should guide students to seriously plan their limited and precious life by standing at the end of life. Nowadays, many college students have a lot of confusion and they idle away the precious time. The school should teach students how to spend their life through life education, help them make clear what they really love and what they will pursue in this life, make them no longer lose and waste time in life, and help them improve the quality of life.

\section{Content Dimension of Life Education}

\subsection{Teach Students to Pay Gratitude for Life}

1) Gratitude for life, from the beginning of life

For most college students, the knowledge of giving birth to life basically comes from several rational common sense listed in biology textbooks. Schools should use more diverse ways to make students learn the hardships and difficulties of ten months' pregnancy and nurturing life. Making students learn the difficulty of nurturing life is to make them understand the value of their own lives, and know that no matter what kind of ups and downs and tortures they will meet in the future, they should not hurt themselves and give up their lives. Cherishing themselves is the greatest filial piety and the most real gratitude for life. Furthermore, the school can conduct survey on some students' parents in the form of offline interviews or online communication, making students feel the love behind their parents' nagging, realize the efforts their parents have made for their growth, and finally make children believe that they all have unique lives worth being cherished.

2) Pay gratitude for life, and know how to appreciate the support from others

Today, students all have more or less self-centered narrow egoism, taking their own demands and the contributions of others for granted. We should educate our students to empathize with others around us, even strangers, to be a warm and affectionate person rather than a egoist, putting aside narrow egoism to help those vulnerable groups in need. At the beginning of the outbreak of the epidemic, China was short of anti-epidemic materials. When we were in danger, overseas Chinese and some friendly countries reached put a helping hand one after another. Japan's Chinese Language Examination Bureau wrote eight big Chinese characters meaning "different countries, shared destinies" on the packaging of anti-epidemic materials for colleges and universities in Hubei Province. Such kindness of offering fuel in snowy weather was highly praised by Chinese netizens on the Internet. Schools should teach students to appreciate the help from others and pay gratitude for mutual support between different lives.

\subsection{Guide Students to Revere Life}

Life is precious, and we should cherish life. However, for young students, this is an empty slogan more than a life experience, because many young people are not willing to savor the connotation carefully.

1) Revering life is to respect others and love all things

First, in terms of revering life, we should not only revere our own life, but also maintain awe of the lives of others. College students are a group advocating their personalities, with the tendency of selfishness, narrowness and self-centered to a certain extent. Whether in daily life or in the process of fighting the epidemic, there are cases that they harm the interests of others for their own interests. We should teach students to face the people around them equally with awe and respect for every life. Secondly, revering life is to love all things. All things have souls, we should face nature with awe, get rid of anthropocentrism, actively implement the philosophy of "unity of nature and man" in Chinese traditional culture, and truly achieve harmony with all things in the world. Colleges and universities should create conditions for students to get close to nature, such as offering the chance for students to 
participate in the greening construction of the campus, cultivate flowers and plants in person, observe and experience the fragility and tenacity of life, to develop students' compassion, making them become an emotional person with a sensitive soul.

2) Guide students to look upon life dialectically

In the traditional life education, it tends more to moral education from both family and school. Both parents and teachers conduct positive education for students, guiding students to think about "What kind of life is valuable?" "How to create a meaningful life?" So, our education lacks guidance for negative experience in life. We should make students understand that life is changeable, and life won't be always easy without twists and turns. Looking upon life with a dialectical attitude means that we are able to not only accept a smooth stage of life, but also face the rough life experience calmly.

After the outbreak of the epidemic, many people fell into panic and couldn't manage their inner fear and anxiety. Therefore, in school education, we need to strengthen the education of dialectical thinking for students in the face of life. Only in this way, when there is a crisis, can we, the individuals, be calm and tackle it in an unhurried manner.

\subsection{Froster Students' Correct View on Life and Death}

Death education first originated in the United States, and it started relatively late in Chinese mainland. Guiding students to confront death can not only alleviate students' fear and anxiety about death, but also make them realize the value of life.

Chinese people always avoid talking about death, but this sudden epidemic makes us understand that death is uncontrollable, which is not exclusive to the patients and the elderly. It can come to each of us at any time. Schools must make students realize that the cessation of life is like the birth of life, which is a natural event. Death is the end of life and the final outcome of life. We are not dead yet, but we must live in the way towards death. This is the fundamental way of our existence. Thinking about death in advance, people will know how to arrange your life, how to live in the present, and how to live a valuable and meaningful life. It is the most important gains for us to think about death.

\subsection{Guide Students to Achieve Life}

Life education should not only guide students to understand life, love life and revere life, but also guide students to think about how to live in harmony with society and nature, how to improve their survival ability and actively realize their life value. Nowadays, there are common cases of learning burnout and living in a dog's life among college students. They are lack of ambitions and fighting spirit. Many students are confused and have no direction of efforts. We should lead students to understand themselves, knowing their talents, what are suitable for them to do and what they really love, to help students establish a clear life orientation, clarify the specific direction of efforts, and formulate their own Long-term career planning.

\section{Life Education should Establish a Normalized Long-term Mechanism}

\subsection{Clarify the Concept of Normalization of Life Education}

Educators must clarify the concept of normalization of life education, include life education into daily teaching plans and evaluate it with credits, to make life education enter the first classroom in an all-round way. Teachers can carry out courses based on the topics of "understanding life, revering life, confronting death and achieving life" with the starting from multiple perspectives such as culture, aesthetics and philosophy. Students can accept the knowledge in a multi-pronged way of taking compulsory courses, elective courses and practical experience courses. They shall not graduate successfully if they fail to obtain the full credits. In addition, the school can also actively make use of the advantages of the Internet, with the help of relevant high-quality courses from other schools and high-quality Internet resources on other platforms, to create a spiritual feast of life education for all students. 
Moreover, it's necessary to normalize art education. Through the setting of courses like music, painting and so on, life education can really be integrated into students' daily life. Activate the vitality of students through artistic edification. Since ancient times, there has been a folk saying that "Diseases arise from anger but be cured by music". Singing and playing musical instruments can vent the bad emotions and stimulate the upward vitality of life. Painting can promote aesthetic taste, and find the fun of the world from the art, as well as the beauty of life around us.

\subsection{Build an Model of Joint Education between Schools and Society}

Life education adheres to the combination of school guidance and extracurricular practice. Social life is the best education. Life education in schools must not be carried out by shutting students up in closed doors. Only by integrating themselves into society, will students have a more in-depth learning experience. Therefore, the school should cooperate with relevant social units or organizations to regularly send students to experience life in the society.

Firstly, schools can establish cooperation with farms. The teacher led the students to the farm to experience farming and sowing, and witness the growth process from a seed to a bud and then to a seedling. In this way, they can feel the sense of achievement of labor and find the tenacious growth vitality of a seed by themselves. This power can make the students reflect on themselves and enhance their courage to create a better life.

Secondly, schools can also cooperate with medical units. The teacher can lead students to volunteer in the hospice ward to accompany patients with seriously illness and think about how to leave with dignity when life is coming to an end. Also, we can lead students to visit funeral homes and cemeteries, guide students to write suicide notes and set epitaphs for themselves, and teach students how to really live towards death.

Finally, schools should create opportunities for students to realize the meaning of "altruism". For example, chances should be provided for students to enter art organizations in society as volunteers, such as choir, calligraphy society, photography association, etc., so that students can improve their own aesthetic quality and artistic standard through contact with professionals, and then give back to the society. Another example, we should encourage students to go into the community on weekends or festivals, do what they can for the people around us or vulnerable groups, such as playing for them with self-made and self-performed literary and artistic programs. On the winter and summer vacations, "three trips to the countryside" activities can be carried out to make students learn to plant with vegetable farmers and fruit farmers, and help them expand sales channels with the advantages of the Internet. In addition, we can also teach rural children reading, reciting, photography, etc. bringing them spiritual consolation. In short, we should make students feel the fun of life, realize the value and significance of life, and finally promote their sense of self-identity in the process of helping others.

\subsection{Create a High Spirited and Upward Cultural Atmosphere in School}

The Long-term edification of school culture is extremely important for life education. People's mental outlook is usually changed unconsciously, which is the subtle power of the environment. Therefore, the school must invest enough in human, material and financial resources to create a high spirited and upward campus atmosphere.

First of all, there must be a special teaching team for life education, which cannot be taught by parttime teachers. Teachers must bring all their energies and focus on the teaching objectives of life education. In addition to formulating theoretical teaching plans, they should also design relevant activity plans. Therefore, the teachers of life education courses are very important. An excellent teacher can not only present high-quality courses and activity design schemes, but also inspire and influence students with his own personality stakes.

Secondly, we should stimulate the vitality of students through recreational and sports activities and competitions. The activities such as basketball matches, football matches, tug of war matches, singing competitions, reading competitions, calligraphy competitions, etc. can not only stimulate students' spirit, but also develop students' ability of teamwork, making them overcome egocentrism, relieve 
their sense of loneliness, learn to respect others and live-in harmony with others, and finally promote their sense of self-identity, which is of great benefit to their physical and mental health.

Thirdly, the campus physical environment should be designed with careful consideration. Schools should attach importance to the significance of the recessive environment on education. Starting from the overall campus environment, educators must start from the details to create a pleasant living environment for students from the selection of slogans to the beautification of walls, from the design of green plants to the style of road signs, from the layout of dormitories to the display of restaurants. For any small designs among them, schools can have students being involved to play their imagination and creativity. For example, competitions can be hold for the design of dormitory culture and classroom wall, so that students can create an elegant-styled and vibrant campus environment with their own wisdom and strength, and make them realize the happiness and value of life as well.

\section{Conclusion}

Heidegger said that, "Poetic inhabit of the earth." The premise of poetic inhabit is to cherish life. Life education is the premise of all educations, and it is also the highest pursuit of education. It is an indisputable fact that the life education for young people is now pretty much the agenda, which is also a major historical issue facing all mankind. Educators must re-examine the problems existing in the existing life education, get back to the original intention of education, and develop young people with vitality, sense of existence and sense of happiness.

\section{References}

[1] Sun Yaosheng and Jiang Yujing. Life education in colleges and universities under the background of COVID-19 [J]. Educator, 2021 (1).

[2] Hu Baozhong, Wang Xiaolei, Meng Lingbo and Wang Shumei. On the education of college students' outlook on life [J]. Journal of Harbin University, 2021 (8).

[3] Han Fang. Key points and principles of life education in different sections under the background of major epidemic [J]. Journal of Luoyang Normal University, 2021 (1).

[4] Cao Huimin. Analysis on the promotional path of college students' life values education in the post epidemic era [J]. Science and Education Forum, 2021 (13).

[5] Ran Yuanmao and Zhao Tingting. Twenty years of life education research: review and prospect [J]. Theory and Practice of Education, 2021 (25). 